\title{
Formando alunos leitores no diálogo entre universidade e escola: a experiência da Ciranda de Leitura de Ciências
}

\author{
Maria Matos* \\ Carla Mendes Maciel** \\ Mariana Lima Vilela***
}

Resumo: Apresentamos a experiência da Ciranda da Leitura de Ciências, parte de um projeto de extensão universitária que busca construir e consolidar os vínculos entre universidade e escolas públicas para o desenvolvimento de programas de formação docente. Desenvolvido simultaneamente no Colégio de Aplicação da UFRJ e no Colégio Estadual Guilherme Briggs, o projeto vem contribuindo tanto para a melhoria das práticas docentes em ação e em formação quanto para as atividades pedagógicas nas relações com a aprendizagem e leitura dos estudantes de nível básico.

Palavras-chave: Leitura, Ciências, Formação docente.

Abstract: We present the experience of Ciranda de Leitura de Ciências, part of a university extension project that seeks to build and consolidate the ties between universities and public schools for the development of teacher training. Developed simultaneously in the Colégio de Aplicação da UFRJ and in the Colégio Estadual Guilherme Briggs the project has contributed both to the improvement of teaching practices in action and in 
training and for educational activities in relations to learning and reading for students of basic level.

Keywords: Reading, Science, Teacher training.

A aquisição da linguagem escrita é reconhecidamente um compromisso da educação escolar, especialmente considerando a importância de leitores maduros e críticos para a construção de uma sociedade democrática (SILVA, 1998). Vivemos em um mundo permeado por uma diversidade de práticas sociais de leitura e escrita, de forma que refletir sobre inclusão social significa também pensar sobre o letramento de nossos alunos. Acreditamos que todo professor, independentemente da disciplina escolar em que atua, deva investir em sua prática no sentido de se tornar corresponsável na condução para uma leitura crítica do mundo.

Baseados nesse pressuposto, o Projeto Ciranda da Leitura de Ciências foi elaborado em 2004, no Colégio de Aplicação da UFRJ. Seus principais objetivos são: desenvolver e amadurecer hábitos de leitura, aprimorar a expressão escrita dos estudantes, bem como enriquecer o processo de construção de explicações e descrições acerca dos conhecimentos escolares em Ciências. Além disso, o desenvolvimento da autonomia, do trabalho coletivo e da responsabilidade dos estudantes, também configuram princípios para o seu desenvolvimento.

O Projeto consiste na organização de uma coleção de livros de distintos gêneros literários como narrativas, livros enciclopédicos, poesias, paradidáticos e de divulgação científica para crianças, relacionados ao conteúdo escolar de Ciências. Tal coleção fica disponível para os alunos ao longo do ano letivo. A cada ano é selecionado um número de livros equivalente ao número de 
estudantes existente nas turmas, de modo que todos eles possam ler simultaneamente e realizar sucessivas trocas de livros. Os alunos são convidados a construir, coletivamente e junto aos professores, as regras para a circulação, para a organização e o controle de entrada e saída dos livros, bem como os cuidados necessários para a preservação dos mesmos. Desse modo, o desenho do Projeto apresenta certa flexibilidade, uma vez que responde aos anseios e às características próprios de cada turma.

Este trabalho tem favorecido significativamente a formação de alunos leitores no segundo segmento do Ensino Fundamental, quando os estudantes estão em fase de amadurecimento dos hábitos de leitura e enfrentando o desafio de se expressar amplamente de forma escrita. Nesse sentido, a Ciranda da Leitura de Ciências contribui tanto para o desenvolvimento da leitura e da escrita quanto para ampliar a visão de mundo e a construção de sentidos e significados sobre as Ciências.

Em 2008, com o objetivo de dar continuidade a esse projeto e ampliar os seus espaços de atuação, buscamos o financiamento da FAPERJ e desenvolvemos o Programa de extensão Integrando a formação inicial e continuada de professores de ciências e biologia na UFRJ que incluiu a realização da Ciranda da Leitura de Ciências simultaneamente no CAp/UFRJ e no Colégio Estadual Guilherme Briggs (CEGUIB). Os recursos do projeto permitiram não somente a aquisição do acervo bibliográfico para as duas escolas, como também a implementação de uma bolsa de apoio técnico para a professora atuante no CEGUIB. A seguir, detalhamos a implementação desse trabalho. 


\section{Implementando a Ciranda de Leitura de Ciências no Colégio Estadual Guilherme Briggs}

O Colégio Estadual Guilherme Briggs (CEGUIB) está localizado no bairro de Santa Rosa, em Niterói, RJ, e atende alunos da Educação Infantil, do Ensino Fundamental, do Ensino Médio, da Educação Especial e da Educação de Jovens e Adultos (EJA) oriundos das comunidades do entorno. Especialmente no Ensino Fundamental, a implementação de propostas pedagógicas frente à heterogeneidade de níveis de desenvolvimento da leitura e da escrita entre os estudantes se constitui como um grande desafio pedagógico. No planejamento das açôes no CEGUIB, passamos a compreender que as dificuldades de leitura e escrita têm afastado cada vez mais nossos alunos dos conteúdos das diversas disciplinas escolares, afinal, na escola, os trabalhos vinculados à construção do conhecimento e ao binômio ensino-aprendizagem caminham através de textos escritos.

Assim, lidar com essa problemática exigiu repensar metodologias, planejamento, materiais e estratégias didáticas que pudessem aumentar o interesse dos alunos pela leitura e, dessa forma, contribuir para a aprendizagem significativa.

Iniciamos então a Ciranda da Leitura de Ciências com a estruturação da coleção de livros que comporiam o projeto tanto no CAp/UFRJ quanto no CEGUIB, em 2008. Diversas reuniões de planejamento e organização do projeto foram realizadas com professores do CAp/UFRJ e do CEGUIB, incluindo professores de Português e a bibliotecária da escola estadual. A partir dessa discussão, as coleções de livros do projeto foram montadas mantendo alguns títulos já utilizados no CAp/UFRJ e acrescentando outros livros infanto-juvenis que apresentassem temáticas presentes no currículo de Ciências do segundo segmento do Ensino Fundamental. Além disso, foi nossa preocupação abranger livros com diferentes linguagens, já que estávamos trabalhando com alunos que apresentavam diferentes níveis de desenvolvimento da leitura e escrita. 
Com base nesses critérios de seleção, iniciamos a compra dos livros e a montagem da coleção. Primeiramente, junto com a bibliotecária do CEGUIB, selecionamos alguns livros da própria biblioteca da escola para fazerem parte da coleção da Ciranda da Leitura de Ciências do CEGUIB. Após essa etapa, visitamos diversas editoras e estudamos os catálogos de livros infanto-juvenis buscando aqueles livros de divulgação científica que pudessem estar adequados ao nosso critério de seleção. Escolhidos os livros, realizamos reunióes conjuntas com os representantes das editoras e realizamos as compras. Ao final desse processo, montamos a coleção (Anexo I).

Com os livros da coleção adquiridos, pudemos começar a Ciranda. Mantendo a forma como esta vem sendo desenvolvida no CAp, a troca dos livros no CEGUIB ocorreu em cada turma e o desenvolvimento do projeto foi discutido e elaborado junto com os alunos. Tal estratégia permitiu que os alunos se sentissem mais próximos do projeto e responsáveis também pelo seu funcionamento e pelo cuidado com os livros. O Projeto atingiu 130 alunos e ocorreu semestralmente em quatro turmas de $7^{\circ}$ ano do Ensino Fundamental, sendo duas no primeiro semestre, e as outras duas, no segundo.

Após o debate coletivo sobre o Projeto em cada turma, decidimos que cada aluno levaria um livro para casa e, por uma semana, seria o responsável por aquele livro, com possibilidade de renovação por mais uma semana (ou mais), se não conseguisse terminar a leitura do livro. Ao final de cada leitura, cada aluno preencheu uma ficha sobre o livro, contendo um pequeno texto e um desenho (Anexo II). Para o controle da troca, fizemos um livro de empréstimos e em cada semana um dos alunos foi responsável por registrar as devoluções e os empréstimos dos livros. A participação dos alunos nesse processo de registro foi importante para produção textual, envolvimento com o projeto, aprendizagem de questões relativas à responsabilidade e organização, e para trabalhar a autoestima com alunos que demandam atenção sobre esse aspecto (por exemplo, alunos de inclusão). Além disso, o fato de a cada semana um aluno diferente ser responsável por esse registro, trouxe discussóes relativas à 
construção e ao funcionamento de projetos coletivos, fundamentais para pensarmos sobre a sociedade atual.

Para marcar o início do projeto, foi realizada a inauguração da Ciranda da Leitura de Ciências (Fig.1), na qual os alunos tiveram o primeiro contato com os livros, encaparam e preparam uma caixa para armazená-los (Fig. 2). Esse momento foi fundamental para garantir o envolvimento dos alunos no projeto.
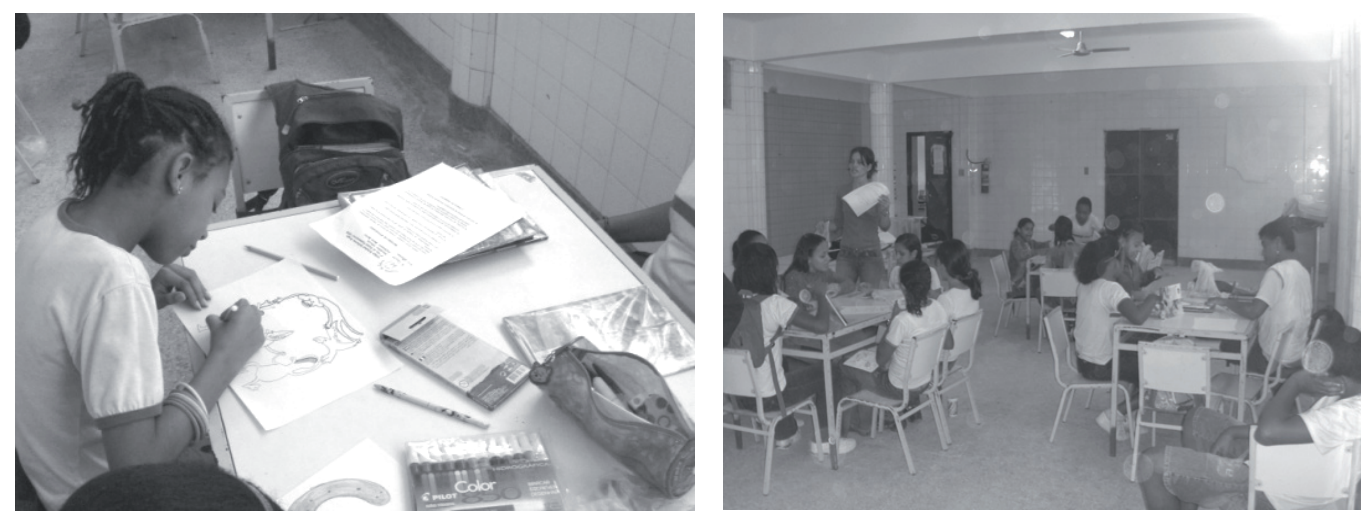

Fig. 1 - Alunos do CEGUIB no início do projeto Ciranda da Leitura de Ciências.
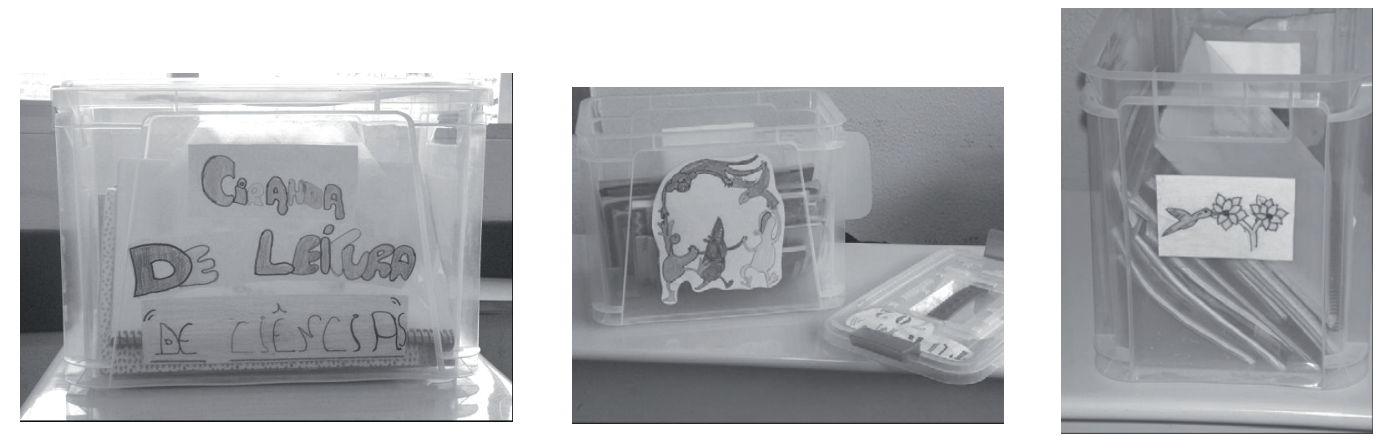

Fig. 2 - Imagens da caixa de armazenamento dos livros decorada pelos alunos do CEGUIB no projeto Ciranda da Leitura de Ciências.

\section{Formando leitores nas aulas de Ciências}

Entre as diversas produções textuais realizadas a partir da Ciranda, as fichas produzidas sobre cada livro lido foram um importante material para acompanharmos as formas como as 
leituras vinham sendo apropriadas pelos alunos. A análise dessas fichas nos permitiu, portanto, avaliar os resultados alcançados. Entre esses, destacamos a melhoria da capacidade de interpretação e de produção textual, o que percebemos pelo amadurecimento da escrita ao longo do projeto.

Nas primeiras fichas apresentadas, a maioria dos alunos desenvolveu uma produção textual muito curta, diversas vezes relatando apenas a opinião sobre o livro e não uma reelaboração do texto conforme solicitado, como nos trechos abaixo, retirados de algumas fichas de leitura:

"Eu gostei do livro. Achei interessante, mas eu não entendi direito".

"Eu achei o livro muito bom. Ele fala muita coisa interessante, eu adorei. Ele ensina muita coisa boa".

"Não gostei muito desse livro".

Porém, com o tempo e o trabalho, os textos foram melhorando e a capacidade de produção textual visivelmente se desenvolvendo:

"Foi muito interessante, mais para quem gosta da natureza. $\mathrm{O}$ livro conta como as plantas produzem seu próprio alimento".

"É sobre uma garotinha que conversava com uma gota d'água. Conta que a gota d'água nasce numa nuvem até ela chegar ao oceano. A Carolina era amiga da gota d'água”.

"Essa revista fala sobre a Amazônia, a origem do nome, os animais que estão em extinção e os dinossauros que há milhões de anos habitavam a Amazônia”.

Percebemos também o envolvimento dos alunos com os livros, através dos desenhos (Fig. 3) e de relatos da participação das famílias no projeto, o que inicialmente não esperávamos, e se tornou uma grata surpresa:

"Eu li sobre as criaturas que vivem debaixo da água [...]. O livro é muito bom, é tão bom que até minha mãe leu". 
"Demorei para devolver o livro porque minha mãe estava copiando as receitas dele".

"Eu gostei do livro porque não foi só eu que li, mas também minha mãe e minha irmã".


Fig. 3: Desenhos de alunos do CEGUIB sobre alguns livros.

Outro resultado demonstrado na produção textual dos próprios alunos foi a ampliação dos conhecimentos científicos e suas relações com o conteúdo discutido nas aulas de ciências, destacada no texto abaixo:

"[...] Eu gostei do livro porque ele fala das plantas e que elas são seres vivos e capazes de se reproduzir, como eu estou aprendendo nas aulas de ciências. Também aprendemos as células das plantas, por isso gostei do livro".

Por relatos orais e discussões na sala de aula, percebemos ainda que os alunos passaram a relacionar os conteúdos curriculares das aulas de ciências com seu dia a dia. E na organização, no controle e no andamento do projeto demonstraram o desenvolvimento de autonomia e responsabilidade. Ficou claro também uma maior integração das turmas, com a participação ativa de todos os alunos no projeto. 


\section{Considerações finais}

No CEGUIB, as atividades da Ciranda da Leitura de Ciências trouxeram avanços não apenas para a prática pedagógica da professora bolsista responsável pelo Projeto como também para outros professores dessa escola. Os resultados refletiram-se nas aulas de Ciências e também em melhorias na aprendizagem da leitura e da escrita em geral, o que constatamos em conversas com outros professores, especialmente a professora de Língua Portuguesa. Além disso, a realização de um Projeto desta natureza na escola estadual alimentou reflexões no interior dessa instituição, favorecendo encontros e diálogos entre professores e funcionários e a exploração de espaços distintos da sala de aula, como a biblioteca. Este processo garantiu a permanência da professora bolsista na instituição para além dos tempos e espaços da sala de aula, contribuindo significativamente para o enriquecimento das práticas escolares como um todo.

Acreditamos que essas práticas foram especialmente influenciadas pelo diálogo com o CAp/UFRJ, já que a interlocução entre os professores é uma das características marcantes do trabalho em equipe desenvolvido tradicionalmente nessa escola na formação de licenciandos. Nesse contexto, a experiência da Ciranda de Leitura de Ciências aqui relatada constituiu-se como um exemplo de ampliação das práticas pedagógicas por meio do diálogo entre universidade e escolas públicas, referendando o potencial de formação continuada dos Colégios de Aplicação.

\section{Referências}

SILVA, Ezequiel Theodoro. Ciência, Leitura e Escola. In: ALMEIDA, Maria José Pereira Monteiro; SILVA, Henrique Cesar. (orgs.) Linguagens, Leituras e Ensino da ciência. Campinas. Mercado de letras: ALB, p.121-130, 1998. 


\section{Anexo I - Livros da coleção da Ciranda de Leitura de Ciências do CEGUIB}

"Almanaque Ruth Rocha”. Ruth Rocha. Editora Ática.

"Eu adoro os animais - E a história... As aventuras do Lobinho Amâncio." Consultora Ana Maria de Souza. Série Saber Mais. Editora Ática.

"Jeca, O Tatu". Ana Maria Machado. Coleção Barquinho de Papel. Editora Ática.

"O Mundo das Plantas - E a história... O amuleto de Yelko." Consultora Deborah Yara Alves Cursino dos Santos. Série Saber Mais. Editora Ática.

"Cavernas". Mario D. Domingos e André C.A. dos Santos. Coleção Investigando o Meio Ambiente.

"Florinha e a fotossíntese". Samuel Murgel Branco. Editora Moderna.

"As aventuras de uma gota d'água". Samuel Murgel Branco. Editora Moderna.

"E a vida continua: a reprodução dos animais e das plantas". Rosicler Martins Rodrigues. Editora Moderna.

"Do campo à mesa - O caminho dos alimentos" Teddy Chu - Cecília Iwashita (Ilus.). Editora Moderna.

"Viagem ao mundo dos micróbios". Samuel Murgel Branco. Editora Moderna.

"Natureza e os seres vivos". Samuel Murgel Branco. Editora Moderna.

"A vida dos dinossauros". Rosicler Martins Rodrigues. Editora Moderna.

"Curupira e o equilíbrio da natureza". Samuel Murgel Branco. Editora Moderna.

"O Saci e a reciclagem do lixo". Samuel Murgel Branco. Editora Moderna.

"O mundo das plantas". Rosicler Martins Rodrigues. Editora Moderna. 
"O solo e a vida". Rosicler Martins Rodrigues. Editora Moderna.

"Vida na Terra: conhecer para proteger" Rosicler Martins Rodrigues. Editora Moderna.

"Vivendo no Cerrado e aprendendo com ele". Marcelo Bizerril. Editora Saraiva.

"Sobrevivendo à grande extinção: dinossauros". Iris Stern. Editora Saraiva.

"Lixo, problema nosso de cada dia". Neide Simões de Mattos; Suzana Fachini Granato. Editora Saraiva.

"Lições da Natureza". Ruth de Gouvêa Duarte. Projeto Ciência. Atual Editora.

"Água: vida e energia". Eloci Peres Rios. Projeto Ciência. Atual Editora.

"O verde e a vida." Sônia Tokitaka; Heloísa Gebara. Coleção de olho na ciência. Editora Ática.

Diversos números da revista "Ciência Hoje das Crianças". Editora SBPC. 
214

Anexo II
